\title{
Parallel expression of macrophage metalloelastase (MMP-12) in duodenal and skin lesions of patients with dermatitis herpetiformis
}

\author{
M T Salmela, S L F Pender, T Reunala, T MacDonald, U Saarialho-Kere
}

\begin{abstract}
Background-Dermatitis herpetiformis (DH) is a specific dermatological manifestation of coeliac disease and $80 \%$ of $\mathrm{DH}$ patients have gluten sensitive enteropathy manifested by crypt hyperplasia and villous atrophy. Matrix degradation mediated by collagenase 1 (MMP-1) and stromelysin 1 (MMP-3) has previously been implicated in the pathobiology of coeliac intestine and cutaneous DH blisters.

Aims-To study expression of stromelysin 2 , metalloelastase, collagenase 3 , and matrilysin in the intestine and skin of $\mathrm{DH}$ patients.
\end{abstract}

Methods-In situ hybridisation using ${ }^{35} \mathrm{~S}$ labelled cRNA probes was performed on duodenal biopsies of $15 \mathrm{DH}$ patients, three samples each of control duodenal or jejunal mucosa, fetal ileal explants, lesional DH skin, and 19 serial biopsies of experimental DH blisters. Immunostaining was used to examine type IV collagen, macrophages (CD68), and 92 kDa gelatinase (MMP-9) in the specimens.

Results-Metalloelastase (MMP-12) was abundantly expressed by subepithelial macrophages in both coeliac intestine and spontaneous and induced DH rash. It was also upregulated in the experimental model of coeliac disease (staphylococcal endotoxin B stimulated fetal explants). The only other MMP detected was MMP-9 which did not colocalise with MMP-12.

Conclusions-Upregulation of metalloelastase is associated with $\mathbf{T}$ cell mediated immune responses both in the intestine and skin. In addition to modulating macrophage migration, it may contribute to degradation of proteoglycans or basement membrane components in the subepithelial mucosa.

(Gut 2001;48:496-502)

Paediatric

Gastroenterology, St

Bartholomew's and the

Royal London School

of Medicine and

Dentistry, London, UK

$S$ L F Pender

T MacDonald

Correspondence to: Dr U K Saarialho-Kere, Department of Dermatology, Helsinki University Central Hospital, Meilahdentie 2, 00250 Helsinki, Finland.

ulpu.saarialho-kere@helsinki.fi

Accepted for publication 25 September 2000

Dermatitis herpetiformis $(\mathrm{DH})$ is a cutaneous disorder characterised by a blistering rash on the elbows, knees, and buttocks, and granular $\operatorname{IgA}$ deposits in the basement membrane (BM) zone. ${ }^{1}$ Although gastrointestinal symptoms in $\mathrm{DH}$ patients are rare, they all have gluten sensitive enteropathy manifested in $80 \%$ by crypt hyperplasia or partial villous atrophy, while the rest have normal villous architecture with increased counts of intraepithelial lymphocytes. ${ }^{2}$ The rash and enteropathy improve on a gluten free diet, implying that $\mathrm{DH}$ is a specific skin manifestation of mainly subclinical coeliac disease (CD). ${ }^{23}$

Matrix metalloproteinases (MMPs) are a family of extracellular matrix (ECM) degrading enzymes that are collectively capable of degrading essentially all ECM components and that can further be subdivided into collagenases (MMP-1, -8, and -13), gelatinases (MMP-2 and -9), stromelysins (MMP-3, -7, -10, and -12), membrane-type MMPs, and other MMPs. ${ }^{45}$ The extracellular activity of MMPs is regulated by TIMPs $1-4 .^{6}$ We have previously reported that expression of MMP-1 and -3 is enhanced in basal keratinocytes surrounding neutrophil abscesses in DH skin. ${ }^{7}$ Furthermore, when producing experimental $\mathrm{DH}$ blisters with $50 \%$ potassium iodide, urokinase plasminogen activator is upregulated at 12 hours, before blisters are seen, while both MMP-1 and MMP-3 are abundantly expressed in 24 hour biopsies of blisters. ${ }^{8}$ In DH, collagenase 1 (MMP-1) and stromelysin 1 (MMP-3) may contribute to formation of blisters by degrading BM components such as type VII as well as type IV collagen or laminin 1, respectively. Interestingly, Daum and colleagues ${ }^{9}$ have recently demonstrated that these same MMPs are expressed by subepithelial macrophages and fibroblasts in intestinal biopsy specimens from patients with CD.

Tissue transglutaminase (tTG) was recently identified as the endomysial antigen in patients with CD. ${ }^{10}$ Patients with $\mathrm{DH}$ have elevated immunoglobulin A autoantibodies to tTG confirming its pathogenic relation with $\mathrm{CD} .{ }^{11}$ tTG has been shown to be involved in the intermolecular cross linking of type VII collagen of anchoring fibrils of skin. Interestingly, type VII collagen is degraded, at least in experimental DH blisters, and expression of both MMP-1 and MMP-3 colocalise in these areas. $^{8}$

The histological changes of CD are characterised by deepening of the crypts and flattening of the villi, and altered turnover of ECM has been implicated in these changes. ${ }^{9}$ Rapid collapse of the villus architecture can occur
Abbreviations used in this paper: $\mathrm{DH}$, dermatitis herpetiformis; MMPs, matrix metalloproteinases; BM, extracellular matrix; SEB, staphylococcal endotoxin B; transforming growth factor $\beta$; GM-CSF, granulocyte macrophage-colony stimulating factor. basement membrane; $\mathrm{CD}$, coeliac disease; ECM, tTG, tissue transglutaminase; IFN- $\gamma$, interferon $\gamma$; IL, interleukin; TNF- $\alpha$, tumour necrosis factor $\alpha$; TGF- $\beta$, 
within hours of administering gliadin to CD patients in vivo. ${ }^{9}$ Daum and colleagues ${ }^{9}$ also recently demonstrated in vivo that MMP-1 may contribute to degradation of interstitial collagens and MMP-3 to epithelial cell shedding in CD. In an experimental model of human fetal small intestine, direct addition of activated MMP-3 in explant cultures caused collapse of the villi within 24 hours. ${ }^{12}$ Furthermore, crypt hyperplasia and villous atrophy rapidly occurred following activation of lamina propria $\mathrm{T}$ cells with the bacterial superantigen Staphylococcus aureus endotoxin B (SEB). ${ }^{13} \mathrm{We}$ have shown that various other MMPs such as stromelysin 2 (MMP-10), matrilysin (MMP7), collagenase 3 (MMP-13), and macrophage metalloelastase (MMP-12) are upregulated in another intestinal disorder, inflammatory bowel disease, characterised by influx of $\mathrm{T}$ cells, eosinophils, and neutrophils, as well as degradation of the mucosa. ${ }^{14} \mathrm{MMP}-10$ has a nearly identical substrate specificity to MMP3. ${ }^{15} \mathrm{MMP}-12$ is the most elastolytic of the MMPs but also degrades various other substrates such as type IV collagen, laminin 1, fibronectin, vitronectin, and proteoglycans. ${ }^{16} 17$ Matrilysin cleaves in vitro collagen type IV, proteoglycans, gelatin, aggrecan, fibronectin, laminin, tenascin, and elastin. ${ }^{18}$ Collagenase 3 degrades fibrillar collagens, gelatin, type IV collagen, tenascin, and fibronectin. ${ }^{19}$ The aim of this study was to further characterise the patterns of MMP expression in $\mathrm{DH}$ intestine. We compared expression of various MMPs in the intestine and skin of patients with $\mathrm{DH}$, and also used the fetal explant model of enteropathy to investigate the link between $\mathrm{T}$ cell activation and MMP production.

\section{Methods}

TISSUES

Fifteen specimens of formalin fixed paraffin embedded duodenal biopsies taken during upper gastrointestinal endoscopy were obtained from the archives of the Department of Dermatopathology, University of Helsinki, Finland. All patients had been diagnosed as having $\mathrm{DH}$ clinically, by demonstration of granular deposits of IgA in the BM zone using immunofluoresence, and by elevated values of IgA gliadin or reticulin antibodies. Eight of 12 patients were endomysial antigen positive at the time of endoscopy. Histologically, six of the samples demonstrated subtotal and the remainder partial villous atrophy (table 1). Cutaneous samples included specimens of lesional skin from patient Nos 13-15. In addition, 19 serial biopsies of experimental $\mathrm{DH}$ blisters were taken four, 12, or 24 hours after application of $50 \%$ potassium iodide, as previously described. ${ }^{8}$ Patients receiving dapsone $(10 / 12)$ were asked to stop their medication 24 hours before the study. Samples taken from 50\% potassium iodide test areas in four healthy volunteers were also examined for control purposes. Histologically normal duodenal $(n=4)$ and jejunal mucosa $(n=3)$ from non-coeliac patients was also analysed. The study was approved by the ethics committee of the
Department of Dermatology, Helsinki University Central Hospital. Informed consent was obtained from individual subjects for all procedures.

\section{IN SITU HYBRIDISATION}

The production and specificity of the antisense human stromelysin 2, macrophage metalloelastase, collagenase 3, and matrilysin probes have been described previously. ${ }^{140-22}$ As a control for non-specific hybridisation, sections were hybridised with ${ }^{35} \mathrm{~S}$ labelled sense RNA from a bovine tropoelastin cDNA. The validity of this probe as a negative control has been confirmed by northern ${ }^{23}$ and in situ hybridisation $^{24}$ assays. The cDNAs were transcribed in vitro using a commercial kit (Promega Corp., Madison, Wisconsin, USA) and labelled with ${ }^{35} \mathrm{~S}$ UTP, as previously described. ${ }^{25}$

Following deparaffinisation and rehydration, $5 \mu \mathrm{m}$ sections were pretreated with $1 \mathrm{mg} / \mathrm{ml}$ of proteinase $\mathrm{K}$ and washed in $0.1 \mathrm{M}$ triethanolamine containing $0.25 \%$ acetic anhydride. Subsequently, sections were hybridised with probes $(2.5-5 \times 104 \mathrm{cpm} / \mu \mathrm{l}$ of hybridisation buffer) and washed under stringent conditions, including treatment with RNAse $\mathrm{A}$, as described previously. ${ }^{25} 26$ Autoradiography was carried out for 20-40 days. All samples were processed in at least two experiments and were independently analysed by two investigators. Samples previously positive for stromelysin 2 (chronic wounds), macrophage metalloelastase (sarcoid granulomas), collagenase 3 (squamous cell carcinomas), and matrilysin (sweat gland tumours) were used as positive controls.

IMMUNOSTAINING

Immunostaining was performed using the avidin-biotin-peroxidase complex technique. ${ }^{25}$ Diaminobenzidine or aminoethylcarbazole (CD20) were used as chromogenic substrates. Monoclonal antibodies included MMP-9 (DB2211; Diabor, Finland $)^{27}$ and CD68 (KP-1, No M814; Dako, Carpinteria, California, USA) to identify macrophages and type IV collagen (M785; Dako, Glostrup, Denmark), and CD20 (L26, M0755) to identify mucosal B cells. Tissues were counterstained with haematoxylin. Staining for revealing elastic fibres was performed using Weigert's elastin stain (Weigert's Resorcin-Fuchsin.).

ORGAN CULTURE OF HUMAN FETAL SMALI INTESTINE

The study received ethics approval from the Hackney and District Health Authority (London, UK). Human fetal small intestine was obtained from the Medical Research Council Tissue Bank, Hammersmith Hospital, London, UK. All specimens used in this study were aged 15-16 weeks' gestation. Culture of human fetal small intestine explants in serum free medium was performed as described previously. ${ }^{28}{ }^{29}$ Mucosal $\mathrm{T}$ cells were activated by adding SEB $(10 \mu \mathrm{g} / \mathrm{ml}$; Sigma $)$ at the onset of culture and tissues were cultured for four days before fixation in formalin and paraffin embedding. 
Table 1 Clinicopathological information and in situ hybridisation results for patients with dermatitis herpetiformis providing duodenal specimens

\begin{tabular}{lllllll}
\hline Age & Sex & Histology & Rash & GFD & MMP-12 & MMP-9 \\
\hline 46 & F & Subtotal & + & + & + & $+\mathrm{nf}, \mathrm{mf}$ \\
17 & F & Subtotal & + & $-/$ & $(+)$ & ++ \\
31 & F & Subtotal & + & - & + & $(+) \mathrm{mf}$ \\
21 & F & Partial & + & - & ++ & $+\mathrm{nf}, \mathrm{mf}$ \\
52 & F & Partial & + & - & ++ & - \\
22 & M & Subtotal & + & - & - & $\mathrm{ND}$ \\
41 & M & Subtotal & + & + & - & $(+) \mathrm{nf}$ \\
30 & M & Partial & - & - & + & + ND, $\mathrm{mf}$ \\
27 & F & Partial & - & $-/+$ & - & $++\mathrm{nf}, \mathrm{mf}$ \\
75 & M & Partial & + & - & ++ & $+\mathrm{nf}$ \\
31 & M & Subtotal & + & -+ & + & ++ nf, mf \\
28 & M & Partial & + & - & + & $(+)$ \\
59 & M & Partial & - & - & + & + \\
33 & F & Partial & + & - & $(+)$ & + \\
36 & M & Partial & + & - & + & + \\
\hline
\end{tabular}

ND, not determined; -, no detectable signal; $(+)$, signal in a few cells; + , specific signal in moderate number of cells; ++ , specific signal in high number of cells. $\mathrm{mf}$, macrophages; $\mathrm{nf}$, neutrophils.

GFD, gluten free diet; +, strict diet; -/+, partial diet; -, no diet.

\section{Results}

INTESTINE

MMP-12 mRNA was detected in 12/15 intestinal biopsies from patients with $\mathrm{DH}$ and most positive cells were detected in samples representing partial villous atrophy (table 1). The plump pale staining macrophage/activated fibroblast-like cells were localised subepithelially (fig 1A, B). At least some of the MMP-12 positive cells were macrophages, as assessed by CD68 immunostaining (fig 1C, D). Although $\mathrm{T}$ cells have been reported to express MMP12 , at least during experimental autoimmune neuritis, ${ }^{30}$ the MMP-12 positive cells did not have histological characteristics of lymphocytes (size, dark nuclear staining). To assess the integrity of the BM in the vicinity of MMP-12 positive cells, type IV collagen immunostaining was performed. It revealed that staining was often blurred in association with the MMP-12 positive areas, suggesting that the BM was not intact (fig $1 \mathrm{~F}, \mathrm{G}$ ). Weigert's stain did not reveal elastic fibres in the MMP-12 positive areas (data not shown). No MMP-12 mRNA positive cells were detected in normal duodenal or jejunal mucosa (fig 1E).

Matrilysin, stromelysin 2, and collagenase 3 were not detected in any of the biopsies. There

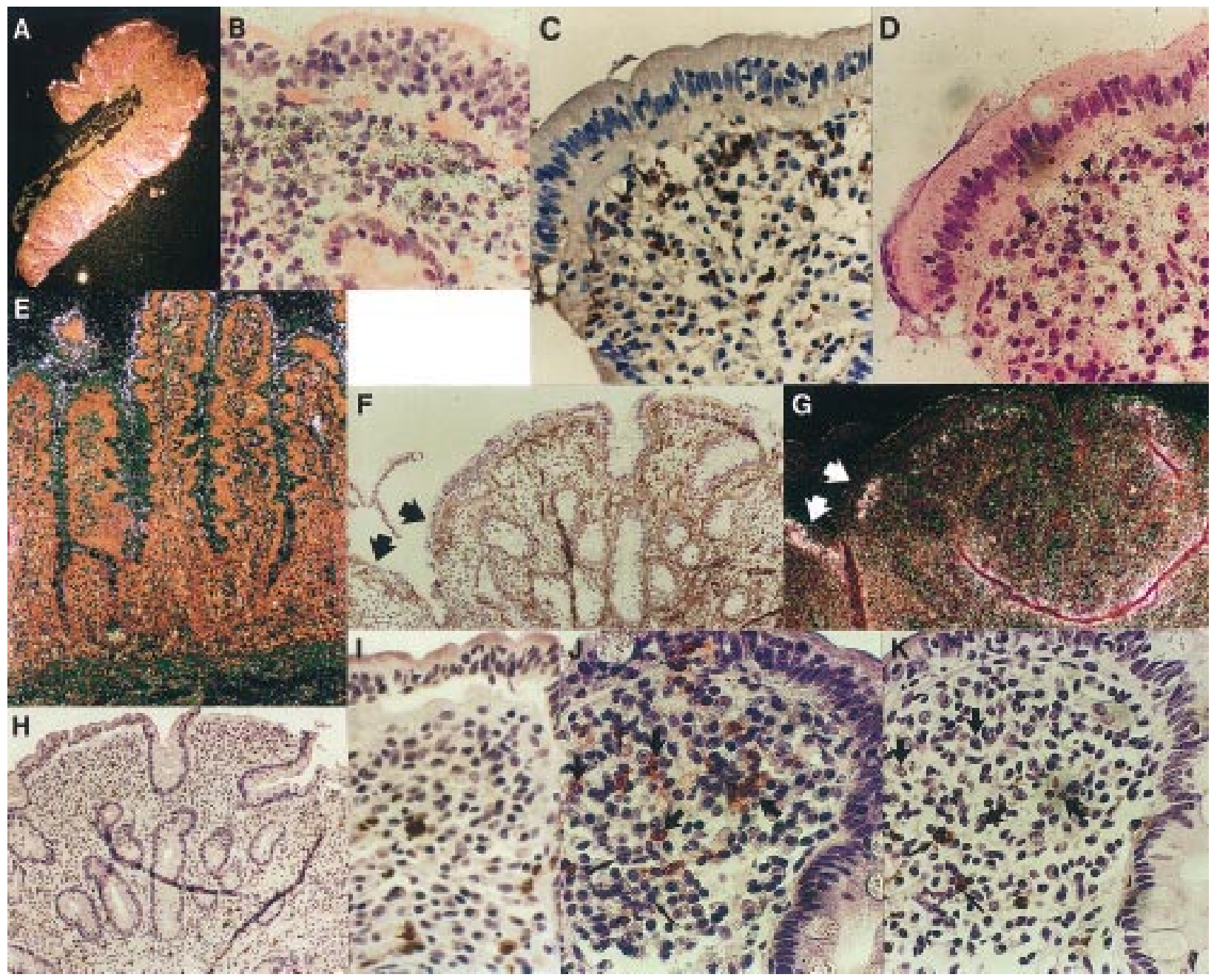

Figure 1 Expression of macrophage metalloelastase (MMP-12) in the subepithelial cell layer of coeliac intestine. (A) A dark field image showing MMP-12 expressed subepithelially in a duodenal biopsy from patient No 10. (B) Higher magnification bright field of the pale plump positive cells under the epithelium. (C) Immunostaining for CD68 macrophage marker. (D) MMP-12 positive cells in a serial section. Arrowheads depict corresponding spots. (E) Normal duodenum is negative for MMP-12 mRNA. $(F, G)$ Serial sections showing MMP-12 in situ hybridisation and staining for type IV collagen. Note the blurred and faint staining in areas with a lot of positive macrophages. Arrows depict corresponding spots. (H) Immunostaining for MMP-9 showing positive cells in different regions than MMP-12. (I) Higher magnification of MMP-9 positive cells seen in (H). (F) Immunostaining for CD20 showing mucosal B cells. (K) Immunostaining for MMP-9 on a serial section. Small arrows show MMP-9 positive but CD20 negative cells, and large arrows depict cells positive for CD20 but negative for MMP-9. Original magnification $\times 20(A), \times 100(E-H)$, and $\times 400(B-D, I-K)$. 


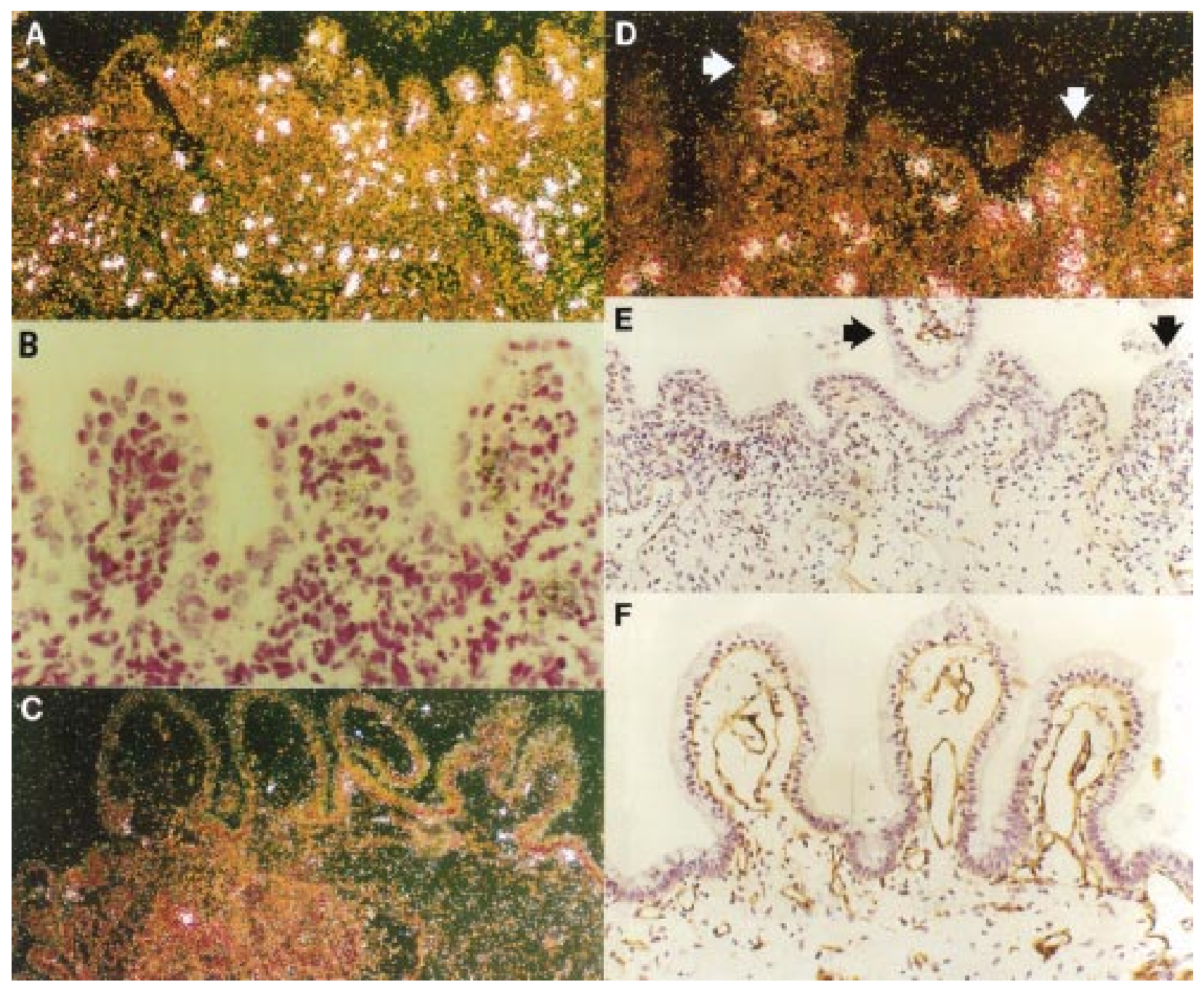

Figure 2 (A) Expression of macrophage metalloelastase (MMP-12) mRNA in a staphylococcal endotoxin B (SEB) stimulated explant cultured for four days. (B) Higher magnification of MMP-12 positive stromal cells under the epithelium. (C) Control explant cultured for four days has occasional

$M M P-12 m R N A$ positive cells. (D) MMP-12 mRNA in another SEB stimulated explant. (E) Type IV collagen staining is abnormal under the atrophic villi. Arrows depict corresponding spots. (F) Type IV collagen immunostaining in the control explant. Original magnification $\times 100(A, C), \times 200(D-F)$, and $\times 400(B)$.

were MMP-9 immunopositive cells in all biopsies and they localised in deeper areas of the mucosa than MMP-12 (fig 1H, D). However, there did not appear to be any correlation between the amounts of MMP-12 or MMP-9 positive cells detected in individual samples (table 1). Staining for CD20 did not colocalise with MMP-9 (fig 1J, K), and hence cells expressing MMP-9 were not B cells, but macrophage-like cells and neutrophils. Occasional MMP-9 positive neutrophils were also detected in normal duodenum (data not shown).

Activation of lamina propria $\mathrm{T}$ cells with SEB results in villous atrophy and crypt hyperplasia, similar to CD. ${ }^{13}{ }^{31}$ In human fetal ileal SEB stimulated explants, MMP-12 was abundantly expressed by macrophages of the stroma and by those trafficking up the villi (fig $2 \mathrm{~A}, \mathrm{~B}$ ). No expression was detected in the control sample harvested two hours after the culture was started on day 1 (data not shown). After four days of culturing, occasional stromal MMP-12 mRNA positive cells were detected in control samples (fig 2C) but their number was significantly lower than in SEB stimulated explants. Staining for type IV collagen revealed that it was abnormal in the flat villi of SEB explants compared with controls (fig 2D-F).

SKIN

Spontaneous DH blisters from patient Nos 13-15 showed MMP-12 mRNA positive macrophages migrating from perivascular inflammatory infiltrates up towards the epidermis (fig $3 \mathrm{~A})$. The BM was partly disrupted in these areas, as assessed by type IV collagen immunodetection (fig 3B). Generally, there was already neutrophil accumulation in the BM zone (fig 3A).

To understand the spatial and temporal induction of MMP-12 in DH, we also studied serial samples from lesions produced by $50 \%$ potassium iodide that were clinically and histologically identical to spontaneous DH blisters, as previously described. ${ }^{8}$ At four hours, excess lymphocytes were seen in the dermis and by 12 hours their number had increased to form perivascular infiltrates, while some areas showed vacuolisation of basal keratinocytes. At 


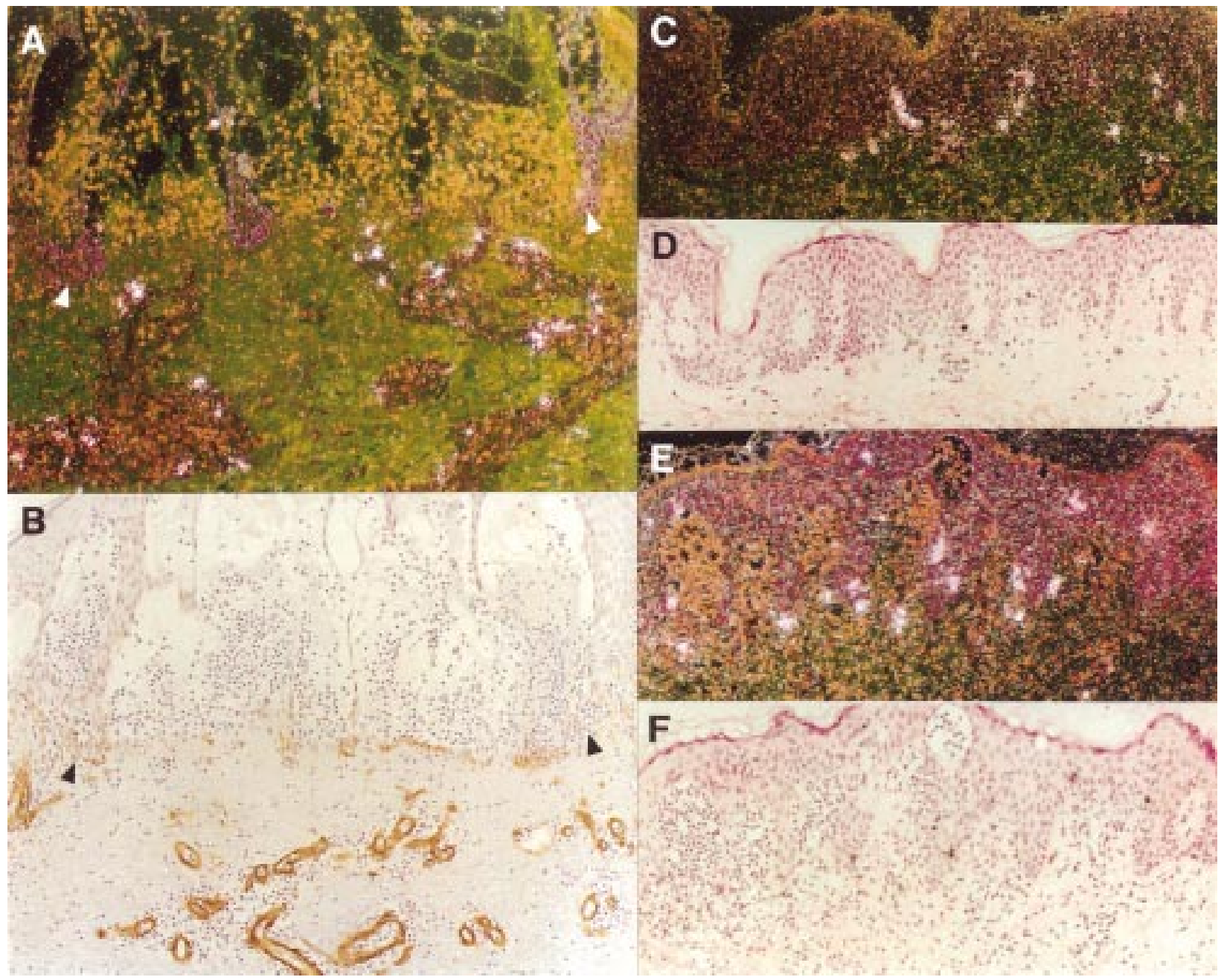

Figure 3 (A) Expression of macrophage metalloelastase (MMP-12) in a spontaneous blister of patient No 3. (B) Staining for type IV collagen in a serial section. Arrowheads depict corresponding spots. (C) MMP-12 positive cells are seen in an induced blister formation at 12 hours. (D) Corresponding bright field image. (E) Dark field image for MMP-12 in situ hybridisation in an induced blister biopsied at 24 hours. (F) Corresponding bright field image. Arrowheads depict corresponding regions. Original magnification $\times 100(A-F)$.

24 hours, typical features included inflammatory cell infiltrates, neutrophilic abscesses with various stages of multilocular blisters, and papillary oedema. The specimens taken from healthy volunteers at $24-48$ hours showed mild eczema but no blister formation. MMP-12 mRNA was not detected in induced blisters biopsied at four hours (data not shown). However, expression was detected in 3/7 12 hour blisters in macrophages of inflammatory infiltrates and those migrating up towards the epidermis (fig 3C, D). In 6/7 24 hour blisters, subepithelial macrophages and some that had already migrated into the epidermis expressed MMP-12 mRNA (fig 3E, F).

Only one of four control specimens of healthy volunteers induced with potassium iodide had occasional MMP-12 mRNA positive cells. It has been reported previously that there are no MMP-12 mRNA positive cells in normal skin. ${ }^{27}$ No MMP-12 positive cells were found in normal looking skin of $\mathrm{DH}$ patients (data not shown).

\section{Discussion}

Dermatitis herpetiformis is a specific dermatological manifestation of $\mathrm{CD}$ with small blisters and pathognomonic IgA deposits in the papillary dermis. ${ }^{32}$ In this study, we have shown that, as previously demonstrated for MMPs- 1 and $-3,{ }^{9}$ expression of MMP-12 was also enhanced in gluten sensitive enteropathy of patients with DH. Furthermore, MMP-12 was also abundantly expressed in macrophages migrating towards and into the epidermis in both spontaneous and induced $\mathrm{DH}$ blisters.

Macrophages are the major cell type known to express MMP-12 in adult tissues and this cell is known to contribute to ECM degradation in various inflammatory conditions. The rapid collapse of villus architecture, which can occur within hours of challenging CD patients with gliadin, has been suggested to be due to degradation of interstitial collagens. ${ }^{9}$ As shown in this study (fig 1), BM disruption also seemed to take place in the intestine of $\mathrm{DH}$ patients. This may be due to MMP-12 in these areas. Alternatively, MMP-12 may be degrading proteoglycans $^{33}$ or other BM components. MMP-12 has been implicated in elastin degradation in the pathogenesis of atherosclerosis and emphysema. ${ }^{34}$ No staining for elastic fibres was detected, even near MMP-12 positive areas, which makes it unlikely that 
MMP-12 participates in elastin remodelling. However, MMPs have many other tasks than matrix remodelling: they function in intestinal mucosal defence by regulating the activity of defensins, ${ }^{36}$ participate in activation of several cytokines, regulate apoptosis, ${ }^{37}$ and may cleave adhesion molecules. ${ }^{38}$

Gluten induced activation of $\mathrm{T}$ cells and secretion of cytokines are believed to be the stimuli for changes in the mucosa of CD and $\mathrm{DH} .{ }^{31}$ Gluten exposure in patients with CD rapidly elicits high levels of interferon $\gamma$ (IFN$\gamma$ ), interleukins (IL) 2,4 , and 6 , and tumour necrosis factor $\alpha(\mathrm{TNF}-\alpha) .{ }^{39}{ }^{40}$ In coeliac intestine, mRNA levels for IL-2, IFN- $\gamma$, TNF- $\alpha$, IL-1 $\beta$, and transforming growth factor $\beta$ (TGF- $\beta$ ) are elevated. ${ }^{41}$ Furthermore, positive immunostaining for TGF- $\beta$ colocalises with MMP-12 in the subepithelial lamina propria. ${ }^{42}$ TNF- $\alpha$, IL- $1 \beta$, macrophage colony stimulating factor, vascular endothelial growth factor, and platelet derived growth factor BB upregulated MMP-12 expression in human peripheral blood derived macrophages, and this induction can be inhibited by TGF- $\beta_{1}{ }^{43}$ In coeliac mucosa, TNF- $\alpha$ is elevated and activation of TGF- $\beta$ may be impaired due to autoantibodies to $\mathrm{tTG}$, both favouring upregulation of MMP-12 in macrophages. In murine peritoneal macrophages, only granulocyte macrophage-colony stimulating factor (GMCSF), but not IFN- $\gamma$, IL-1 $\beta$, IL-2, IL-5, IL-6, or $\mathrm{TNF}-\alpha$, can induce metalloelastase production. ${ }^{44}$ Interestingly, increased expression of GM-CSF has been reported in lesions of $\mathrm{DH} .{ }^{8}$ Moreover, eosinophils in CD secrete GM$\mathrm{CSF}^{45}$ and could thus contribute to upregulation of MMP-12 in intestinal macrophages. In addition to cytokine stimulation, direct contact with $\mathrm{T}$ cells may also upregulate MMP-12 expression in mucosal macrophages. ${ }^{46}$

In contrast with inflammatory bowel disease, ${ }^{14}{ }^{47} \mathrm{MMP}-7,-10$, and -13 mRNA positive cells could not be found in atrophic intestinal biopsies from patients with DH. MMP-7 and -10 were also not expressed in $\mathrm{DH}$ lesions. Furthermore, none of the MMPs investigated in this study was detected in mucosal epithelium. This suggests that mucosal reepithelialisation is needed to induce MMPs in enterocytes. ${ }^{14} 47$

We also demonstrated that MMP-12 was markedly upregulated in an experimental model of CD - namely, fetal intestinal explants stimulated by SEB. Resident lamina propria cells are activated by SEB to produce $T$ helper 1 (Th)-type cytokines and within 2-4 days there is crypt hyperplasia, a typical feature of CD. ${ }^{31}$ However, the ex vivo system does not contain neutrophils, B cells, mast cells, or eosinophils. ${ }^{12}$ This suggests that proinflammatory cytokines can induce MMP-12 expression in resident lamina propria macrophages. SEB stimulation results in some loss of lamina propria glycosaminoglycans, ${ }^{48}$ which are in vitro substrates, or both MMP-3 and MMP-12. ${ }^{17} 19$ Furthermore, keratinocyte growth factor and TGF- $\alpha$ are known to be upregulated in SEB stimulated explants ${ }^{49}$; however, there are no reports on the regulation of MMP-12 by these cytokines. SEB activation of T cells also causes increased concentrations of MMPs-1, $-2,-3$, and -9 , and TIMP $-1,{ }^{47}$ as seen in CD in vivo.

MMP-12 was abundantly expressed in both spontaneous and induced $\mathrm{DH}$ blisters. The mechanism by which potassium iodide provokes blistering in $\mathrm{DH}$ is not known but the reaction is characteristic of $\mathrm{DH}$, and healthy controls do not get blisters. ${ }^{8} \mathrm{MMP}-12$ expression at 12 hours coincides with that of urokinase plasminogen activator in basal keratinocytes but precedes induction of MMPs-1 and $-3 .{ }^{8}$ Based on our histological data on the distribution of MMP-12 mRNA and the integrity of the BM, as assessed by type IV collagen staining, it seems that degradation of the BM is initiated before MMP-12 positive macrophages have migrated into the epidermis (fig 3) and that it is associated with neutrophil accumulation.

Activated macrophages are generally thought to contribute to mucosal damage via secretion of cytokines such as IL-1 $\beta$ and TNF- $\alpha$. The results of this study suggest that by secreting MMP-12, they can contribute to $\mathrm{BM}$ changes and perhaps epithelial cell loss. MMP-12 may modulate macrophage influx into inflammatory sites by cleaving endothelial or epithelial BMs. Furthermore, MMP-12 is capable of activating $\mathrm{TNF}-\alpha^{15}$ and may thereby stimulate the inflammatory response in CD. tTG with plasmin is required for proteolytic activation of TGF- $\beta .^{50}$ If inhibition of tTG by coeliac autoantibodies indeed blocks tTG bioactivity and thus prevents TGF- $\beta$ activation, ${ }^{51}$ it is probable that various MMPs are upregulated as TGF- $\beta$ generally results in their downregulation. ${ }^{4}$ In conclusion, our results demonstrate that in $\mathrm{DH}$, both intestinal and skin manifestations could be partly caused by proteases secreted by activated macrophages. In the future, use of selective MMP-12 inhibitors or anti-TNF- $\alpha$ antibody therapy may prove beneficial in alleviating the cutaneous symptoms and intestinal manifestations of $\mathrm{DH}$.

We thank Dr Kristiina Airola for taking the skin biopsies, the Ventana Medical Systems for the use of their immunodetection machine, Mrs Alli Tallqvist for excellent technical assistance, and Drs Steven Shapiro, Veli-Matti Kähäri, and Lynn Matrisian for plasmids. This study was supported by grants from the Academy of Finland, the Sigrid Juselius Foundation, and the Helsinki University Central Hospital Research Fund, and Crohn's in Childhood Research Association (CICRA), UK.

1 Gawkrodger DJG, Backwell JN, Gilmour HK, et al. Dermatitis herpetiformis: diagnosis, diet and demography. Gut 1984;25:151-7.

2 Mäki M, Collin P. Coeliac disease. Lancet 1997;349:1755-9.

3 Reunala T. Dermatitis herpetiformis: coeliac disease of the skin. Ann Med 1998;30:416-18

4 Kähäri V-M, Saarialho-Kere UK. Matrix metalloproteinases in skin. Exp Dermatol 1997;6:199-213.

5 Shapiro SD. Matrix metalloproteinase degradation of extracellular matrix: Biological consequences. Curr Opin Cell Biol 1999;10:602-8.

6 Gomez DE, Alonso DF, Yoshiji H, et al. Tissue inhibitors of metalloproteinases: structure, regulation and biological functions. Eur $\mathcal{F}$ Cell Biol 1997;74:111-22.

7 Airola K, Vaalamo M, Reunala T, et al. Enhanced expression of interstitial collagenase, stromelysin-1 and urokinase plasminogen activator in lesions of dermatitis herpetiformis. F Invest Dermatol 1995;105:184-9.

8 Airola K, Reunala T, Salo S, et al. Expression of urokinase plasminogen activator preceeds collagenase, stromelysin-1, and laminin-5 in lesions of dermatitis herpetiformis. $\mathcal{f}$ Invest Dermatol 1997;108:7-11.

9 Daum S, Bauer U, Foss H-D, et al. Increased expression of mRNA for matrix metalloproteinases- 1 and -3 and tissue 
inhibitor of metalloproteinases-1 in intestinal biopsy specimens from patients with coeliac disease. Gut 1999;44:1725.

10 Dieterich W, Ehnis T, Bauer M, et al. Identification of tissue ransglutaminase as the autoantigen of celiac disease. Nat Med 1997;32:1129-33.

11 Dieterich W, Laag E, Bruckner-Tuderman L, et al. Antibodies to tissue transglutaminase as serologic markers in patients with dermatitis herpetiformis. F Invest Dermatol 1999;113:133-6.

12 Pender SL, Tickle SP, Docherty AJ, et al. A major role for matrix metalloproteinases in $\mathrm{T}$ cell injury in the gut. $f$ Immunol 1997;160:4098-103.

13 Lionetti P, Breese EJ, Spencer J, et al. Activation of V $\beta 3+\mathrm{T}$ cells and tissue damage in human small intestine induced by the bacterial superantigen, Staphylococcus aureus endotoxin. Eur f Immunol 1993;23:664-8.

14 Vaalamo M, Karjalainen-Lindsberg M-L, Puolakkainen P, et al. Distinct expression profiles of stromelysin-2 (MMPal. Distinct expression profiles of stromelysin-2 (MMP10), collagenase 3 (MMP-13), macrophage metalloelastase (TIMP-3) in intestinal ulcerations. Am f Pathol 1998;152: (TIMP-3)

15 Nagase H. Stromelysins 1 and 2. In: Parks WC, Mecham $\mathrm{RP}$, eds. Matrix metalloproteinases. New York: Academic Press, 1998:43-84

16 Chandler S, Miller KM, Clements JM, et al. Matrix metalloproteinases, tumor necrosis factor and multiple sclerosis: an overview. $\mathcal{F}$ Neuroimmunol 1997;72:155-61.

17 Gronski TJ, Martin RL, Kobayashi DK, et al. Hydrolysis of a broad spectrum of extracellular matrix proteins by human macrophage elastase. F Biol Chem 1997;272:1218994.

18 Murphy G, Cockett MI, Ward RV, et al. Matrix metalloproteinase degradation of elastin, type IV collagen and proteoglycan. A quantitative comparison of the activities of $95 \mathrm{kDa}$ and $72 \mathrm{kDa}$ gelatinases, stromelysins- 1 and -2 and punctuated metalloproteinase (PUMP). Biochem f 1991; punctuated

19 Knäuper V, Lopez-Otin C, Smith B, et al. Biochemical characterization of human collagenase-3. F Biol Chem 1996; 271:1544-50.

20 Saarialho-Kere UK, Pentland AP, Birkedal-Hansen H, et al. Distinct populations of basal keratinocytes express stromelysin-1 and stromelysin-2 in chronic wounds. $\mathcal{F}$ Clin Invest 1994;94:79-88.

21 Vaalamo M, Mattila L, Johansson N, et al. Distinct populations of stromal cells express collagenase-3 (MMP-13) and collagenase-1 (MMP-1) in chronic ulcers but not in normally healing wounds. F Invest Dermatol 1997;109:96101 .

22 McDonnell S, Navre M, Coffrey RJ, et al. Expression and localization of the matrix matalloproteinase Pump-1 (MMP-7) in human gastric and colon carcinomas. Mol Carcinogenesis 1991;4:527-33.

23 Stahle-Bäckdahl M, Parks WC. 92-kDa gelatinase is actively expressed by eosinophils and stored by neutrophils in expressed by eosinophils and stored by neutrophils in

24 Saarialho-Kere U, Chang ES, Welgus HG, et al. Distinct localization of collagenase and TIMP expression in wound localization of collagenase and TIM expression in wound Clin Invest 1992;90:1952-7.

25 Saarialho-Kere UK, Kovacs SO, Pentland AP, et al. Cell-matrix interactions modulate interstitial collagenase expression by human keratinocytes actively involved in wound healing. F Clin Invest 1993;92:2858-66.

26 Prosser IW, Stenmark KR, Suthar M, et al. Regional heterogeneity of elastin and collagen gene expression in intralobar arteries in response to hypoxic pulmonary hypertension as demonstrated by in situ hybridization. An f Pathol 1989;135:1073-88.

27 Vaalamo M, Kariniemi A-L, Shapiro SD, et al. Enhanced expression of human metalloelastase (MMP-12) in cutaneous granulomas and macrophage migration. F Invest Dermatol 1999;112:499-505.

28 MacDonald TT, Spencer J. Evidence that activated mucosal $\mathrm{T}$ cells play a role in the pathogenesis of enteropathy in cells play a role in the pathogenesis of enteropathy
human small intestine. $\mathcal{F}$ Exp Med 1988;167:1341-9.

29 Lionetti P, Breese E, Braegger CP, et al. T-cell activation can induce either mucosal destruction or adaptation in cultured human fetal small intestine. Gastroenterology 1993 105:373-81.
30 Hughes PM, Wells GM, Clements JM, et al. Matrix metalloproteinase expression during experimental autoimmune loproteinase expression during exp
neuritis. Brain 1998;121:481-94.

31 MacDonald TT, Bajaj-Elliott M, Pender SLF. T cells orchestrate intestinal mucosal shape and integrity. Immunol Today 1999;20:505-10.

32 Collin P, Reunala T, Rasmussen M, et al. High incidence and prevalence of adult coeliac disease: augmented diagnostic approach. Scand f Gastroenterol 1997;32:112933.

33 Pender SLF, Lionetti P, Murch SH, et al. Proteolytic degradation of intestinal mucosal extracellular matrix after lamina propria T cell activation. Gut 1996;39:284-90.

34 Halpert I, Sires UI, Roby JD, et al. Matrilysin is expressed by lipid-laden macrophages at sites of potential rupture in atherosclerotic lesions and localizes to areas of versican deposition, a proteoglycan substrate for the enzyme. Proc Natl Acad Sci USA 1996;93:9748-53.

35 Hautamäki RD, Kobayashi DK, Senior RM, et al. Requirement for macrophage elastase to cigarette-smoke-induced emphysema in mice. Science 1997;277:2002-4.

36 Wilson CL, Quellette AJ, Satchell DP, et al. Regulation of intestinal $\alpha$-defensin activation by the metalloproteinase matrilysin in innate host defense. Science 1999;286:113-16.

37 Powell WC, Fingleton B, Wilson CL, et al. The metalloproteinase matrilysin proteolytically generates active soluble fas ligand and potentiates epithelial cell apoptosis. Curr Biol 1999;9:1441-7.

38 Perry I, Tselepis C, Hoyland J, et al. Reduced cadherin/ catenin complex expression in celiac disease can be reproduced in vitro by cytokine stimulation. Lab Invest 1999;79: 1489-99.

39 Kontakou M, Przemioslo RT, Sturgess RP, et al. Cytokine mRNA expression in the mucosa of treated celiac patients after wheat peptide challenge. Gut 1995;37:52-7.

40 Nilsen EM, Jahnsen FL, Lundin KEA, et al. Gluten induces an intestinal cytokine response strongly dominated by interferon gamma in patients with celiac disease. Gastroenterology 1998;115:551-63.

41 Lahat N, Shapiro S, Karban A, et al. Cytokine profile in coeliac disease. Scand f Immunol 1999;49:441-6.

42 Lionetti P, Pazzaglia A, Moriondo $M$, et al. Differing patterns of transforming growth-factor-beta expression in normal intestinal mucosa and in active celiac disease. 7 Pediatr Gastroenterol Nutr 1999;29:310-13.

43 Feinberg MW, Jain MK, Werner F, et al. TGF-beta 1 inhibits cytokine-mediated induction of MMP-12 in macrophages. f Biol Chem 2000;275:25766-73.

44 Kumar R, Dong Z, Fidler IJ. Differential regulation of metalloelastase activity in murine peritoneal macrophages by granulocyte-macrophage colony-stimulating factor and macrophage colony-stimulating factor. F Immunol 1996;1: 5104-11

45 Desmeuraux P, Delaporte E, Colombel JF, et al. Similar IL-5, IL-3, and GM-CSF syntheses by eosinophils in the jejunal mucosa of patients with celiac disease and dermatitis herpetiformis. Clin Immunol Immunopathol 1998;88:1421.

$46 \mathrm{Wu} \mathrm{L}$, Fan J, Matsumoto S, et al. Induction and regulation of matrix metalloproteinase- 12 by cytokines and CD40 signaling in monocyte/macrophages. Biochem Biophys Res Comm 2000;269:808-15.

47 Saarialho-Kere U, Vaalamo M, Puolakkainen $\mathrm{P}$, et al. Enhanced expression of matrilysin, collagenase, and stromelysin-1 in gastrointestinal ulcers. Am F Pathol 1996; 148:519-26

48 Pender SLF, Breese EJ, Gunther U, et al. Suppression of T cell-mediated injury in human gut by interleukin 10: role of matrix metalloproteinases. Gastroenterology 1998;115:57383.

49 Bajaj-Elliott M, Poulsom R, Pender SLF, et al. Interactions between stromal cell-derived keratinocyte growth factor and epithelial transforming growth factor in immunemediated crypt cell hyperplasia. f Clin Invest 1998;102: 1473-80.

50 Schuppan D, Dieterich W, Riecken EO. Exposing gliadin as a tasty food for lymphocytes. Nat Med 1998;4:666-7.

51 Halttunen T, Mäki M. Serum immunoglobulin A from patients with celiac disease inhibits human T84 intestinal crypt epithelial cell differentiation. Gastroenterology 1999;
116:566-72. 